\title{
The Energy Return on Energy Investment (EROI) of Photovoltaics: Methodology and Comparisons with Fossil Fuel Life Cycles
}

Marco Raugei ${ }^{*}{ }^{1,2}$, Pere Fullana-i-Palmer ${ }^{1}$ and Vasilis Fthenakis ${ }^{2,3}$

${ }^{1}$ UNESCO Chair in Life Cycle and Climate Change, Escola Superior de Comerç Internacional (ESCI) - Universitat Pompeu Fabra, 08003 Barcelona, Spain

${ }^{2}$ Center for Life Cycle Analysis, Columbia University, New York, NY 10027, USA

${ }^{3}$ National Photovoltaic Environmental Research Center, Brookhaven National Laboratory, Upton, NY 11973, USA

* Corresponding author. Tel.: +34 9329547 10, Fax.: +34 9329547 20, E-mail:marco.raugei@esci.upf.edu

\begin{abstract}
:
A high energy return on energy investment (EROI) of an energy production process is crucial to its long-term viability. The EROI of conventional thermal electricity from fossil fuels has been viewed as being much higher than those of renewable energy life-cycles, and specifically of photovoltaics (PVs). We show that this is largely a misconception fostered by the use of outdated data and, often, a lack of consistency among calculation methods. We hereby present a thorough review of the methodology, discuss methodological variations and present updated EROI values for a range of modern PV systems, in comparison to conventional fossil-fuel based electricity life-cycles.
\end{abstract}

Keywords: EROI; photovoltaics. 


\section{Introduction}

The flourishing of most modern societies has largely been made possible through the exploitation of vast reserves of fossil carbon, such as petroleum oil, natural gas and various grades of coal (Cleveland et al., 1984; Hall et al., 2008; Murphy and Hall, 2011). Conventional oil and gas reserves are being depleted at an increasingly fast rate, both domestically in the USA and globally. In fact, there is strong evidence that we may be rapidly approaching what is often referred to as ṕeak oilô i.e. the absolute peak in global production, generally assumed to correspond to the point at which half of the economically extractable cumulative reserves have been consumed (Campbell and Laherre, 1998). Even more worrisome is the related fact that what is left is becoming increasingly more costly to extract, both in economic and in net energy terms (Hall and Cleveland, 1981; Cleveland, 2005; Hall and Day, 2009; Gagnon et al., 2009; Murphy and Hall, 2010; Murphy and Hall, 2011).

The energy return on energy investment (EROI) indicator was introduced to provide a numerical quantification of the benefit that the user gets out of the exploitation of an energy source, in terms of thow much energy is gained from an energy production process compared to how much of that energy (or its equivalent from some other source) is required to extract, grow, etc., a new unit of the energy in questionò(Murphy and Hall, 2010). In the case of a fossil fuel, EROI is calculated as the ratio of the energy in a given amount of the extracted and delivered fuel $\left(E_{\text {Feed }}\right)$ to the total primary energy used in the supply chain $\left(E_{E D}\right.$, i.e. the energy that is directly and indirectly required to extract, refine and deliver the fuel):

Eqn. 1) $\quad \mathrm{EROI}_{\mathrm{F}}=\mathrm{E}_{\mathrm{Feed}} / \mathrm{E}_{\mathrm{ED}}$

The EROI of oil and natural gas has shrunk from higher than 100 (for domestic US oil at the wellhead) in the 1930क्s (Cleveland et al., 1984; Cleveland, 1992;

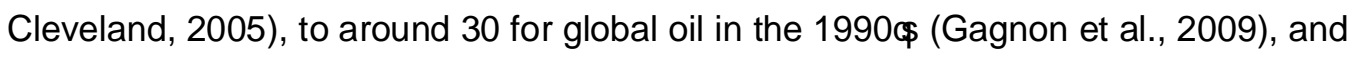


down to approximately 20 by now (Gagnon et al., 2009; Murphy and Hall, 2011). Even lower values, closer to 10 , have been estimated for specific fields that are getting closer to exhaustion (Cleveland, 2005; Hall et al., 2008; Guilford et al., 2011; King and Hall, 2011).

Calculated EROI values for coal are in the 40 to 80 range (Cleveland et al., 1984; Hall and Day, 2009; King, 2010), and appear to have thus far mostly remained relatively stable, since coal reserves are farther from being depleted. However, coal is a less flexible fuel than oil or gas, it cannot be directly used to power vehicles, and its combustion invariably entails higher environmental impacts, in terms of greenhouse gases, sulphur oxides and particle emissions.

As societies evolve, they often come to rely more and more heavily on electricity as a ubiquitous and versatile energy carrier. To date, approximately $80 \%$ of global electricity is of fossil origin, with oil- and gas-fired power plants providing over $30 \%$ of the total (IEA, 2008). The decreasing EROls of oil and gas reserves therefore negatively impact electricity generation too, since less net energy is available in the first place to produce it.

Renewableôelectricity generation technologies (i.e. those that rely on renewable primary energy as their main energy input) still provide only a small percentage of global electricity generation, but their market shares are growing steadily; in particular, the installed photovoltaic (PV) capacity has undergone a ten-fold increase over the last five years (Kautto and Jaeger-Waldau, 2009). Increased market penetration of PV technologies has also been paralleled by incremental improvements in their environmental performance, as amply documented by a large body of scientific literature (Fthenakis and Alsema, 2006; Raugei et al., 2007; Fthenakis et al., 2009; Held and Ilg, 2011; Fthenakis and Kim, 2011).

The relative performance of $\mathrm{PV}$ in terms of $\mathrm{EROI}$, however, has so far been impaired by a dearth of clearly defined and consistently framed comparative studies. Several published studies have indicated PV (and to a lesser degree also wind) as 
having often discouragingly low EROI, when compared to conventional fossil-based energy (Hall et al., 2008; Hall, 2008; Hall and Day, 2009; Murphy and Hall, 2010; Heinberg, 2009; Kubiszewski and Cleveland, 2009; Lloyd and Forest, 2010). We herein provide a careful systematic discussion of the underlying assumptions and calculations, and provide new calculations based on the latest published life cycle analyses of PV systems.

\section{Methodological issues}

While it might appear deceptively simple at first sight, the discipline known as Net Energy Analysis, of which the EROI indicator is one of the most famous outcomes, is ridden with many insidious caveats which, unless carefully considered and clearly addressed, risk turning the whole approach into an exercise in futility. This fact has been widely acknowledged since the early days of the method, and has been the object of continued discussion ever since (Slesser, 1974; Leach, 1975; Chambers et al., 1979; Herendeen, 1988; Cleveland, 1992; Herendeen, 2004; Mulder and Hagens 2008).

In this section, we aim at providing a balanced discussion of what we consider to be the main methodological issues that have so far resulted in a lack of consistency among the many calculated values for the $\mathrm{EROI}$ of $\mathrm{PV}$, especially when set against the backdrop of conventional fossil-fuel electricity.

\subsection{Energy investments and Primary Energy Sources vs. Energy Carriers}

First of all, as obvious as it may sound, the calculation of the energy return on investment (EROI) of a system demands a clear and unambiguous definition of which of the energy inputs over its entire life cycle are to be classified as ónvestmentsô Such classification, and hence the resulting EROI, is ultimately determined by the choice of system space and time boundaries, and if the results 
are to be compared to those for different systems (e.g. PV vs. conventional fossil fuel-based electricity), it becomes absolutely essential that the calculation procedure be applied in a consistent manner.

A second fundamental distinction is that between Primary Energy Sources (PES) and Energy Carriers (EC). As stated multiple times in the history of net energy analysis, and recently reprised clearly and concisely by Murphy and Hall, r̃a primary energy source is an energy source that exists in nature and can be used to generate energy carriers (e.g., solar radiation, fossil fuels, or waterfalls). An energy carrier is a vector derived from a primary energy source (e.g., electricity, gasoline, or steam)ò (Murphy and Hall, 2011).

Regrettably, a clear definition of system boundaries is missing in many published EROI studies of electricity production. In those studies in which a classification of the energy inputs is provided, the common practice is to draw the system boundaries so as to include the construction and end-of-life of the power plant structure as part of the energy ónvestmentô

This is illustrated in Figure 1 for a generalized electricity production system, where:

- $\mathrm{E}_{\mathrm{FF}} \quad=$ non-renewable PES in the ground (e.g. crude oil)

- $\mathrm{E}_{\mathrm{Feed}} \quad=$ energy of extracted and delivered EC (e.g. heavy fuel oil)

= direct non-renewable energy input for electricity production (feedstock)

- $\mathrm{E}_{\mathrm{ED}} \quad=\mathrm{E}_{\mathrm{Feed}} / \mathrm{EROI}_{\mathrm{F}}($ see Eqn. 1)

= energy for the supply chain (extraction and delivery) of the feedstock, expressed in terms of (renewable + non-renewable) Primary Energy

- $\mathrm{E}_{\mathrm{PP}} \quad=$ energy for the construction and end-of-life (EoL) of the power plant, expressed in terms of (renewable + non-renewable) Primary Energy

- $\mathrm{E}_{\mathrm{R}}=$ direct renewable Primary Energy input for electricity production (usually excluded from the EROI calculations)

- $\mathrm{E}_{\mathrm{OUT}}=$ net electricity $(\mathrm{EC})$ output 
All input and output energy flows are computed over the entire lifetime of the system.

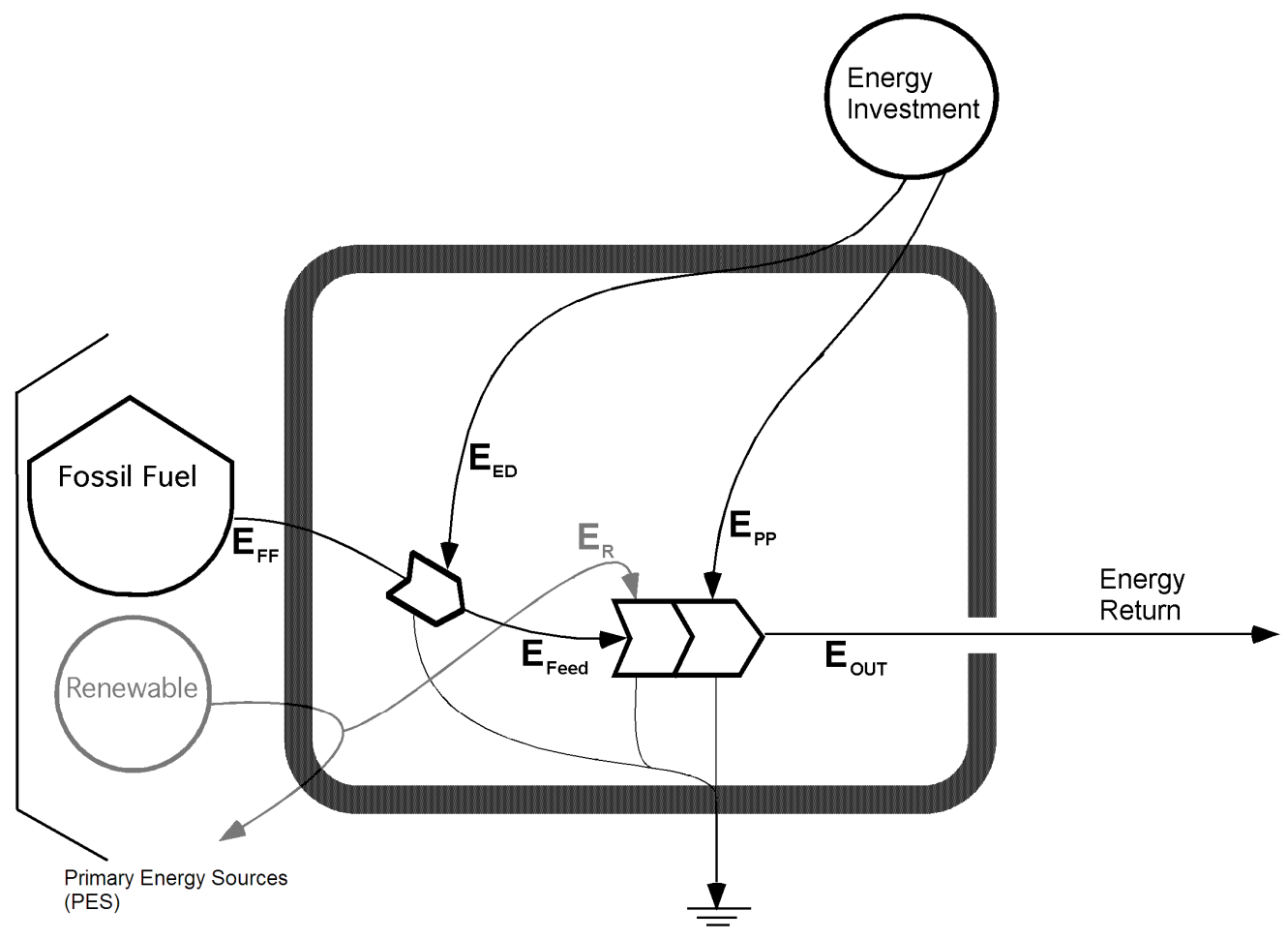

Figure 1 System boundaries for EROI analysis of a generalized electricity production system.

It should be noted that the same diagram applies to both conventional thermal systems (where $E_{F e e d}$ is the energy in the feedstock fuel driving the system, and $E_{R}$ is the renewable energy of the wind needed to disperse the combustion gases at the stack) and óenewableô systems (where $E_{F e e d}$ and $E_{E D}$ are zero, and $E_{R}$ is the renewable energy driving the system, e.g. sunlight for PV).

The resulting widely accepted formula for the EROI of the produced electricity is:

$$
\mathrm{EROI}_{\mathrm{el}}=\mathrm{E}_{\mathrm{OUT}} / \mathrm{E}_{\mathrm{INV}}=\mathrm{E}_{\mathrm{OUT}} /\left(\mathrm{E}_{\mathrm{ED}}+\mathrm{E}_{\mathrm{PP}}\right)
$$

This essentially corresponds to answering this type of question: WWe have some energy in hand $\left(\mathrm{E}_{\mathrm{ED}}+\mathrm{E}_{\mathrm{PP}}\right)$; how much energy return ( $\left.\mathrm{E}_{\mathrm{OUT}}\right)$ do we get if we invest it 
to (1) build a power plant $\left(E_{P P}\right)$ and (2, where required by the technology being analyzed) extract and deliver $\left(E_{E D}\right)$ some fossil fuel feedstock to operate it to produce electricity?ò

Incidentally, it should be acknowledged that the formal distinction between ๓eedstockôenergy $\left(E_{F e e d}\right)$ and đ́energy investmentô( $\left.E_{E D}+E_{P P}\right)$ is somewhat arbitrary: in practical terms, both are crucial contributors to the system $\hat{\mathbf{s}}$ functioning over its

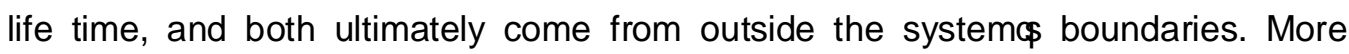
precisely, the feedstock fuel ćxtraction and deliveryôprocess is included within the analyzed system, but its output ( $\mathrm{E}_{\mathrm{Feed}}$ ) is driven by a (larger) input of non-renewable Primary Energy from an outside fossil fuel reservoir $\left(E_{F F}\right)$. A direct input of renewable energy from outside the system $\left(E_{R}\right)$ is also always required, for both ǿenewableôand conventional power systems (e.g. PV requires sunlight, and a coal power plant requires wind for dispersing the combustion gases and other pollutants emitted at the stack).

As a result, it must be kept in mind that the EROI metric is not to be interpreted as an overall measure of primary energy demand per unit of energy output, or a sort of đife cycle energy conversion efficiencyô In fact, by way of how the EROI ratio is defined, the two largest direct energy inputs to the system $\left(E_{F e e d}\right.$ and $\left.E_{R}\right)$ are not accounted for as part of the denominator, which instead only includes the primary energy previously invested to make them available $\left(E_{E D}\right)$, plus the further investment in terms of the primary energy required for the power plant ( $\left.E_{P P}\right)$.

This has profound policy implications that must be kept in mind at all times.

What EROI really indicates is how éasyô (in energy terms) it is to exploit the available Primary Energy Sources $\left(E_{F F}+E_{R}\right)$, by ónvestingô a given amount of energy which one already has at one $\hat{\Phi}$ disposal (the latter energy investment $=E_{E D}$ $+E_{P P}$ is obviously made in the form of readily usable Energy Carriers, but it is accounted for in terms of the underlying Primary Energy). 
Thus, EROI provides a good indication of the benefit that a society may get by choosing one q́rimary energy exploitation systemô in times of relative abundance of that form of primary energy. In other words, it tends to favour those systems that produce the best øang for the buckô $\left(E_{O U T} /\left(E_{E D}+E_{P P}\right)\right)$, irrespective of how much energy is directly required to flow through the system in absolute terms in order to sustain the production of one unit of energy output $\left(\left(E_{F_{e e d}}+E_{R}\right) / E_{O U T}\right)$. Also, importantly, EROI does not differentiate between renewable and non-renewable primary energy inputs, and is thus blind to the overall amount of non-renewable energy $\left(E_{F e e d}+\right.$ the non-renewable portion of $E_{E D}$ and $\left.E_{P P}\right)$ that is consumed per unit of energy output, i.e. to how quickly the system is geared to deplete the nonrenewable primary energy resources on which it feeds. As a result, when two alternatives are compared, the one having the higher EROI may at the same time be the one which entails the faster depletion of high-quality non-renewable primary energy stocks, per unit of energy output. Hence, taken in isolation, EROI is arguably a rather poor indicator of the long-term sustainability of an energy exploitation system, and making far-reaching policy decisions only based on this one metric is not recommendable.

\subsection{PV electricity and its 'Primary Energy equivalent'}

In the existing literature on PV systems, one of the most commonly employed indicator of their energy performance is the Energy Pay-Back Time (EPBT), defined as (Fthenakis and Kim, 2011; Fthenakis et al., 2011; Raugei, 2011):

Eqn. 3) $\quad$ EPBT $=\mathrm{E}_{\mathrm{PP}} / \mathrm{E}_{\mathrm{OUT} \text {-eq,yr }}$

- $\mathrm{E}_{\mathrm{PP}} \quad=$ energy for the construction and end-of-life (EoL) of the PV power plant, expressed in terms of (renewable + non-renewable) Primary Energy

- $\mathrm{E}_{\mathrm{OUT}-\mathrm{eq}, \mathrm{yr}}=$ net yearly electricity output, expressed in terms of equivalent Primary Energy 
EPBT (measured in years) is meant to denote how long it takes for a PV system to produce enough electricity to offset to the cumulative Primary Energy required to build (and later decommission) the system $\left(E_{P P}\right)$. The conversion from the yearly electricity output (an Energy Carrier) to its équivalent Primary Energyôis normally done on the basis of the dife cycle energy conversion efficiencyô of the current electric grid $\left(d_{\text {grid }}\right)$, i.e. $E_{\text {OUT-eq,yr }}=E_{\text {OUT,yr }} / d_{\text {grid }}$, where for instance $d_{\text {grid }}=0.29$ for the USA, and $d_{\text {grid }}=0.31$ for the EU-27 (Ecoinvent, 2011).

In order to relate EPBT to EROI, the following formula has been used (Hall, 2008; Heinberg, 2009; Lloyd and Forest, 2010):

Eqn. 4)

$$
\begin{aligned}
& \text { EROI }_{\text {PE-eq }}=\mathrm{T} / \mathrm{EPBT}= \\
& =\mathrm{T} \cdot\left(\mathrm{E}_{\mathrm{OUT}-\mathrm{eq}, \mathrm{yr}} / \mathrm{E}_{\mathrm{PP}}\right)=\mathrm{T} \cdot \mathrm{E}_{\mathrm{OUT}, \mathrm{yr}} /\left(\mathrm{E}_{\mathrm{PP}} \cdot \mathrm{d}_{\text {grid }}\right)= \\
& =\mathrm{E}_{\mathrm{OUT}} /\left(\mathrm{E}_{\mathrm{PP}} \cdot \mathrm{d}_{\text {grid }}\right)
\end{aligned}
$$

where $\mathrm{T}=$ system $\hat{\mathbf{S}}$ lifetime.

It is noteworthy that this differs from Eqn. 2 in Section 2.1, in that the net energy output over the PV system $\hat{\Phi}$ lifetime in Eqn. 4 is expressed in terms of its $\mathbb{\oplus}$ rimary Energy equivalentô $\left(E_{\mathrm{OUT}} / \mathrm{d}_{\text {grid }}\right)$, and not directly as electricity $\left(\mathrm{E}_{\mathrm{OUT}}\right)$. All else being equal, the EROI resulting from the application of Eqn. 4 is thus higher by a factor of $\left(1 / d_{\text {grid }}\right)$ than that resulting from Eqn. 2.

Unanimous agreement is lacking in the published literature, and sometimes the EROI of PV (as well as that of other renewables like wind energy) is instead computed without the prior conversion of the generated electricity into its primary energy-equivalent, i.e. according to Eqn. 2 (Kubiszewski and Cleveland, 2009; Kubiszewski et al., 2010). Also, in virtually all published studies, the simple (yet potentially ambiguous) term đROlô is invariably used, without any specifying subscripts such as the ones introduced here. This lack of consistency among the 
published studies has been a source of confusion and lack of comparability, which has occasionally been made worse by the omission of any clear indication of the adopted convention (Hall and Day, 2009).

We argue that, by expressing $E_{\text {OUT-eq }}$ in terms of its Фrimary Energy equivalentôand

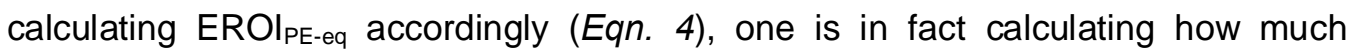
Primary Energy is virtually ǿeturnedôto society (i.e. preserved for alternative uses) per unit of Primary Energy invested in PV, given the composition of the current electric grid. This being the case, such EROI should not be directly compared to that of conventional (e.g. oil- or coal-fired) electricity, which is always computed according to Eqn. 2.

Instead, the EROl fossil fuels as such (e.g. oil or coal), assuming in first approximation that the energy in the extracted and delivered fuels (Energy Carriers, to which $\mathrm{EROI}_{\mathrm{F}}$ as per Eqn. 1 strictly refers), is only negligibly different from that contained in the respective raw fuels (Primary Energy Sources). From a pragmatic point of view, such approximation is fully acceptable, given the inherent variability and uncertainty in the quantitative estimate of the numerical value of $\mathrm{EROI}_{\mathrm{F}}$.

\section{New calculations}

Besides methodological inconsistencies, another reason for the low EROI numbers for PV often reported in the hitherto published literature has been the use of outdated data. Using up-to-date values for PV systems is especially important, given the extremely fast rate of technological change in the current dynamic situation. In fact, combining the technical specification of modern state-of-the-art commercial modules with performance ratios derived from extensive experimental field data is arguably the most valid approach to assessing the level of energy performance that can be expected of a PV system today. Conversely, defaulting to measured 
electricity generation records from existing installations only returns an aggregated measure of the performance of a long chain of system components, some of which are likely to be no longer representative of the current state of technological advancement, and is therefore not a viable alternative if one wishes to faithfully portray a technology that is still in such a state of flux.

We herein present the results of our new EROI calculations for a range of modern PV systems (mono-crystalline $\mathrm{Si}$, multi-crystalline $\mathrm{Si}$, ribbon $\mathrm{Si}$ and $\mathrm{CdTe}$ thin film), based on the most recent published LCA studies by ourselves and other colleagues (Fthenakis et al., 2009; Held and Ilg, 2011; Fthenakis and Kim, 2011).

Data were normalized to assume conservative performance ratios (PR) of $75 \%$ for rooftop mounted systems and $80 \%$ for ground mounted optimal latitude installations, which also implicitly account for module degradation (Fthenakis et al., 2011). In all cases, the complete PV system was addressed, including all balance of system (BOS) components, and the analysis was extended to the full life cycle, including take back and recycling, and assuming an industry-standard PV system lifetime (T) of 30 years (Fthenakis et al., 2011). We also adopted the average southern European ground-level insolation, i.e. $1,700 \mathrm{kWh} /\left(\mathrm{m}^{2} \cdot \mathrm{yr}\right)$, which incidentally coincides with the mean global insolation (horizontal surface) in between the Arctic and Antarctic circles (NASA, 2008). Finally, the EU-27 electric grid efficiency ( $d_{\text {grid }}=$ 0.31) was used, when called for, to convert the electricity generated by PV into its Фrimary Energy equivalentô in accordance with the common practice for EPBT calculations.

Our full EROI calculations for PV are illustrated in Table 1.

For comparative purposes, we also calculated the EROI of oil- and coal-fired thermal electricity. We took the primary energies required for the respective power plants $\left(E_{P P}\right)$ and the total direct inputs of feedstock energies over their 30-year lifetimes $\left(E_{F e e d}\right)$ from the reputable LCA database Ecoinvent v.2 (Jungbluth, 2007; 
Dones et al., 2007; Ecoinvent, 2011); we then back-calculated $E_{E D}$ for each as $\mathrm{E}_{\mathrm{Feed}} / \mathrm{EROI}_{\mathrm{F}}$

Our full EROI calculations for oil- and coal-fired thermal electricity are illustrated in Tables 2 and 3. 
Table 1 EROI calculations for PV. LCI data from (Fthenakis et al., 2009; Held and Ilg, 2011; Fthenakis and Kim, 2011)

\begin{tabular}{|c|c|c|c|c|c|}
\hline Ref. Eqn. & & Mono-c Si (rooftop) & Multi-c Si (rooftop) & Ribbon Si (rooftop) & CdTe (ground) \\
\hline & Insolation $\left[\mathrm{kWh} /\left(\mathrm{m}^{2} \cdot \mathrm{yr}\right)\right]$ & 1,700 & 1,700 & 1,700 & 1,700 \\
\hline & Performance Ratio & 0.75 & 0.75 & 0.75 & 0.8 \\
\hline & $\mathrm{E}_{\mathrm{OUT}, \mathrm{yr}}\left[\mathrm{kWh} \mathrm{h}_{\mathrm{el}} /\left(\mathrm{m}^{2} \cdot \mathrm{yr}\right)\right]$ & 179 & 166 & 166 & 150 \\
\hline & $\mathrm{T}[\mathrm{yr}]$ & 30 & 30 & 30 & 30 \\
\hline \multirow[t]{3}{*}{ Eqn. 2} & $\mathrm{EROI}_{\mathrm{el}}=\mathrm{E}_{\mathrm{OUT}} / \mathrm{E}_{\mathrm{PP}}$ & 5.9 & 5.9 & 9.4 & 11.8 \\
\hline & $\mathrm{d}_{\text {grid }}$ & 0.31 & 0.31 & 0.31 & 0.31 \\
\hline & $\begin{array}{l}E_{\text {OUT-eq,yr }}=E_{\text {OUT,yr }} / d_{\text {grid }} \\
{\left[\mathrm{MJ}_{\mathrm{PE}-\mathrm{eq}} /\left(\mathrm{m}^{2} \cdot \mathrm{yr}\right)\right]}\end{array}$ & 2,073 & 1,925 & 1,925 & 1,737 \\
\hline
\end{tabular}

(a) It is noted that current efficiencies of mono-c Si and CdTe PV are slightly higher than those stated here; correspondingly, their EROls are also higher.

Subscripts to energy units stand for: el = electricity; PE = Primary Energy; PE-eq = Фrimary energy equivalentô(based on dgrid). 
Table 2 EROI calculations for oil-fired thermal electricity. $\mathrm{LCl}$ data from (Ecoinvent, 2011; Jungbluth, 2007)

\begin{tabular}{|c|c|c|c|}
\hline Ref. Eqn. & & minimum & maximum \\
\hline & $\mathrm{EROI}_{\mathrm{F}}$ & 10 & 30 \\
\hline & $\mathrm{E}_{\mathrm{PP}}\left[\mathrm{MJ}_{\mathrm{PE}} /(\right.$ plant unit)] & $1.90 \cdot 10^{9}$ & $1.90 \mathrm{E} \cdot 10^{9}$ \\
\hline & $\begin{array}{l}\text { PP units per } k W h_{\text {el }} \text { output } \\
{\left[(\text { plant units }) / \mathrm{kWh}_{\mathrm{el}}\right]}\end{array}$ & $1.18 \cdot 10^{-11}$ & $1.18 \cdot 10^{-11}$ \\
\hline & $\mathrm{E}_{\mathrm{PP}}\left[\mathrm{MJ}_{\mathrm{PE}} / \mathrm{kWh}_{\mathrm{el}}\right]$ & $2.24 \cdot 10^{-2}$ & $2.24 \cdot 10^{-2}$ \\
\hline & E $_{\text {OUt }}\left[\mathrm{kWh}_{\mathrm{el}}\right]$ & 1 & 1 \\
\hline & $\mathrm{E}_{\text {Feed }}\left[\mathrm{MJ}_{\mathrm{PE}} / \mathrm{kWh}_{\mathrm{el}}\right]^{(\mathrm{a})}$ & 9.5 & 9.5 \\
\hline & $\begin{array}{l}\mathrm{E}_{\mathrm{ED}}=\mathrm{E}_{\mathrm{Feed}} / \mathrm{EROI}_{\mathrm{F}} \\
{\left[\mathrm{MJ}_{\mathrm{PE}} / \mathrm{kWh}_{\mathrm{el}}\right]}\end{array}$ & 0.95 & 0.32 \\
\hline Eqn. 2 & $\mathrm{EROI}_{\mathrm{el}}=\mathrm{E}_{\mathrm{OUT}} /\left(\mathrm{E}_{\mathrm{PP}}+\mathrm{E}_{\mathrm{ED}}\right)$ & 3.7 & 10.6 \\
\hline
\end{tabular}

(a) Weighted average for European (UCTE) oil-fired electricity.

Subscripts to energy units stand for: el = electricity; PE = Primary Energy.

Table 3 EROI calculations for coal-fired thermal electricity (without Carbon Capture and Storage). LCl data from (Ecoinvent, 2011; Dones et al., 2007)

\begin{tabular}{|l|l|c|c|}
\hline Ref. Eqn. & & minimum & maximum \\
\hline & EROI & $\mathbf{4 0}$ & $1.60 \mathrm{E} \cdot 10^{9}$ \\
\hline & $\mathrm{E}_{\mathrm{PP}}\left[\mathrm{MJ}_{\mathrm{p}} /(\right.$ plant unit) $]$ & $2.68 \mathrm{E} \cdot 10^{9}$ & $1.31 \cdot 10^{-11}$ \\
\hline & $\begin{array}{l}\text { PP units per } \mathrm{kWh} \\
{[(\text { plant } \text { output }}\end{array}$ & $1.04 \cdot 10^{-11}$ & \\
\hline & $\mathrm{E}_{\mathrm{PP}}\left[\mathrm{MJ}_{\mathrm{PE}} / \mathrm{kWh} \mathrm{h}_{\mathrm{el}}\right]$ & & $2.09 \cdot 10^{-2}$ \\
\hline & $\mathrm{E}_{\mathrm{OUT}}\left[\mathrm{kWh} \mathrm{h}_{\mathrm{el}}\right]$ & $2.79 \cdot 10^{-2}$ & 1 \\
\hline & $\mathrm{E}_{\mathrm{Feed}}\left[\mathrm{MJ}_{\mathrm{PE}} / \mathrm{kWh}_{\mathrm{el}}{ }^{(\mathrm{a})}\right.$ & 10.7 & 10.1 \\
\hline
\end{tabular}




\begin{tabular}{|l|l|c|c|}
\hline & $\begin{array}{l}\mathrm{E}_{\mathrm{ED}}=\mathrm{E}_{\mathrm{Feed}} / \mathrm{EROI} \\
{\left[\mathrm{MJ}_{\mathrm{PE}} / \mathrm{kWh}_{\mathrm{Fl}}\right]}\end{array}$ & 0.27 & 0.13 \\
\hline Eqn. 2 & EROI $_{\mathrm{el}}=\mathrm{E}_{\mathrm{OUT}} /\left(\mathrm{E}_{\mathrm{PP}}+\mathrm{E}_{\mathrm{ED}}\right)$ & $\mathbf{1 2 . 2}$ & $\mathbf{2 4 . 6}$ \\
\hline
\end{tabular}

(a) Weighted averages respectively for European (UCTE) lignite-fired electricity (óninimumôcolumn) and hard coal-fired electricity (ónaximumôcolumn).

Subscripts stand for: el = electricity; PE = Primary Energy .

\section{Discussion}

Starting with the most straightforward approach, i.e. adopting the system boundaries illustrated in Figure 1 and applying Eqn. 2, we may compare the ensuing EROI $\mathrm{el}_{\mathrm{el}}$ PV electricity to the $\mathrm{EROI}_{\mathrm{el}}$ ranges for oil-and coal-fired thermal electricity (Figure 2).

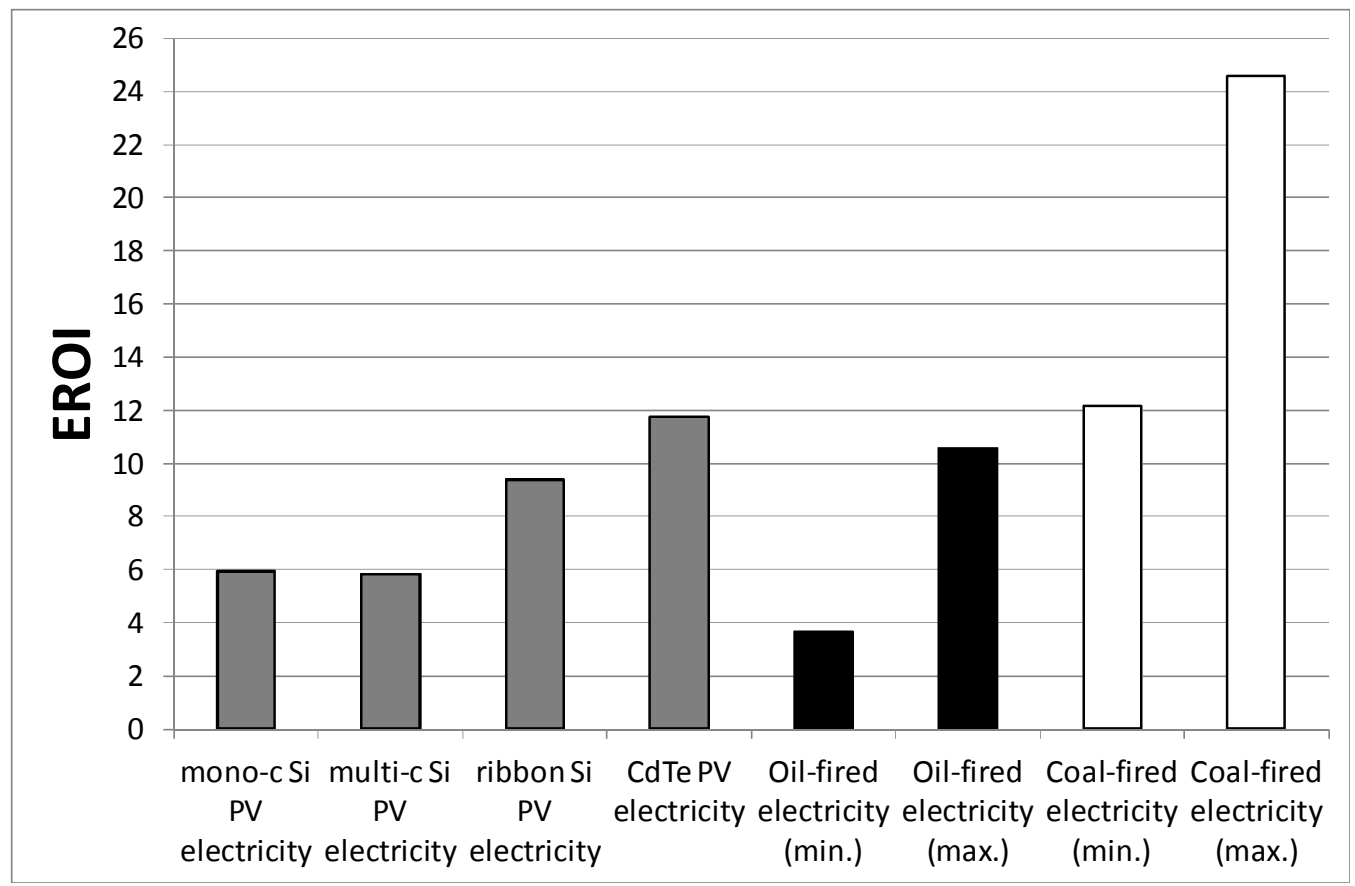

Figure $2 \quad \mathrm{EROI}_{\mathrm{el}}$ of PV electricity, compared to the $\mathrm{EROI} \mathrm{e}_{\mathrm{el}}$ of oil- and coal-fired thermal electricity (Eqn. 2) 
These results show that, when accounting for the ệnergy returnôas a straight Energy Carrier (i.e. electricity as such), the resulting $\mathrm{EROI}_{\mathrm{el}}$ of $\mathrm{PV}$ spans approximately the same range $\left(E R O I_{e l}\right.$ å 6 ï 12) as the $E_{R O l}$ of conventional oilfired electricity systems $\left(E R O I_{\text {el }}\right.$ a 4 ï 11$)$, while the $E R O I_{\text {el }}$ of coal-fired electricity systems come out approximately double of that of PV (EROI $\mathrm{el} 12$ ï 24). However, it should not be forgotten that thermal electricity production, and coal-fired systems in particular, suffer from much higher life-cycle greenhouse gas emissions than PV (Fthenakis and Kim, 2011), which would be energy-intensive to reduce by means of carbon capture and storage (CCS), thereby considerably reducing the final $E R O I_{\mathrm{el}}$. These results show that investing energy to build and operate PV power systems or conventional fossil fuel-based electricity generation systems are, today, essentially comparable options in terms of the amount of electricity delivered (ǿeturnedô over the 30 years of their operational lifetimes. Of course, a crucial difference between PV and the two conventional systems remains, though, which the EROI indicator was never designed to address: conventional thermal electricity production systems achieve their (́⿴nergy returnsôby depleting limited stocks of non-renewable primary energy $\left(E_{F e e d}\right)$, while in the case of PV systems the corresponding direct input of energy consists of flow-limited but virtually inexhaustible renewable energy $\left(E_{R}\right)$.

Remarkably, the more recently introduced PV technologies (ribbon Si and especially CdTe thin film) lie at the upper end of the $\mathrm{EROI}_{\mathrm{el}}$ range, despite their shorter ramp up time and overall comparatively less mature development status. This potentially bodes well for the future, since it is reasonable to expect further improvements for the next generations of these technologies.

We may alternatively choose to calculate the $\mathrm{EROI}_{\mathrm{PE}-\mathrm{eq}}$ of $\mathrm{PV}$ according to Eqn. 4, thereby expressing the PV electricity output in terms of its Drimary Energy equivalentô as explained in Section 2.2, these results may be compared to the range of $\mathrm{EROI}_{F}$ for oil and coal (Figure 3). 


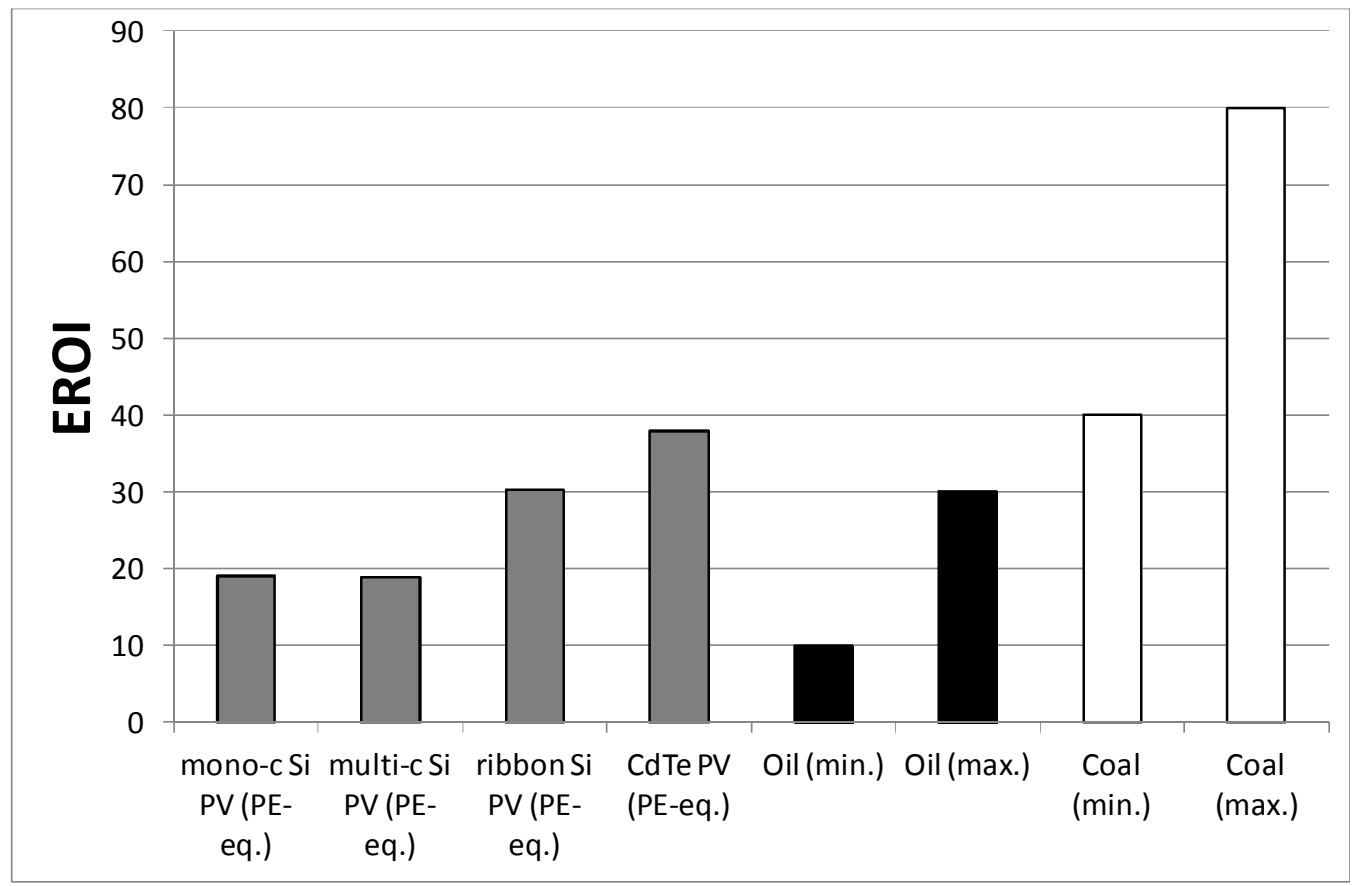

Figure 3 EROI ${ }_{\mathrm{PE}-\mathrm{eq}}$ of PV electricity (in terms of its Primary Energy equivalent), compared to the $\mathrm{EROI}_{\mathrm{F}}$ of oil and coal (EROI ${ }_{\mathrm{PE}-\mathrm{eq}}$ of $\mathrm{PV}$ is back-calculated on the basis of the average grid efficiency according to Eqn. 4; infrastructure investments to resolve intermittency and make PV electricity a continuous energy source that is fully functionally equivalent to a fuel, are not included).

As expected, applying Eqn. 4 results in higher EROl ${ }_{\mathrm{PE}-\mathrm{eq}}$ for the PV systems vs. the corresponding $E R O I_{e l}$, exactly by a factor of $\left(1 / d_{\text {grid }}\right)=3.2$. This new comparison shows that the equivalent primary energy that is virtually 'returned' to society (i.e. preserved for alternative uses) when one chooses to invest a given amount of primary energy to build and operate a PV system is actually marginally higher $\left(\mathrm{EROI}_{\mathrm{PE}-\mathrm{eq}}=19\right.$ ï 38 , mean $\left.=28.5\right)$ than the average energy delivered by oil itself, were one to invest the same amount of primary energy at hand in extracting and delivering that oil $\left(\mathrm{EROI}_{\mathrm{F}}=10\right.$ ï 30 , mean $\left.=20\right)$. Coal, as a fuel, is instead characterized by a more favourable energy return on energy investment $\left(\mathrm{EROI}_{\mathrm{F}}=\right.$ 
40 ï 80 , mean $=60$ ); however, it must not be overlooked that coal is a less flexible and more polluting energy carrier than oil, which needs to be liquefied (or even converted to electricity) before it can be used for a number of important end uses (e.g. modern high-efficiency internal combustion or electric engines for transportation), with concomitant energy losses that will result in a reduction in its final EROI at the point of use.

\section{Outlook}

It is important to stress that the EROI results for PV presented here cannot be simply extrapolated to the future. On one hand, technological improvements are expected to continue providing incremental life cycle energy efficiency gains to the existing PV technologies, and even radically more efficient, third-generation devices might become available in the long run. On the other hand, PV is not a base-load technology, and deploying it on a large scale, beyond approximately $20 \%$ of grid penetration, may require building an extensive energy storage infrastructure (Denholm and Margolis, 2006; Lewis, 2007). To date, compressed air energy storage (CAES) is the least expensive large-scale option, but finding appropriate porous media underground reservoirs is a challenge and a conventional CAES plant requires approximately $3.5 \mathrm{MJ} / \mathrm{kWh}$ of additional natural gas to heat the compressed air when the latter is released to run a gas turbine (Mason et al., 2008). Advanced adiabatic CAES (AA-CAES) might become viable in the future, with an anticipated $50 \%$ cycle efficiency (Pickard et al., 2009); flexible fabric structures anchored to the seabed are also being investigated for their potential to be a clean, economicallyattractive means of energy storage (Pimm and Garvey, 2009).

Most importantly, a fully-fledged long-term analysis of the EROI of PV vs. conventional energy generation cannot be done by analysing the individual systems in isolation. Such analysis would instead require accounting for combinations of 
different renewable energy generation systems, their interconnections and storage to satisfy regional or global load demands (Nikolakakis and Fthenakis, 2011). Also, as deployment increases, minor additional losses in life cycle efficiency might at times be caused by the necessity to compensate for intermittency with lowerefficiency marginal technologies.

Additionally, as discussed elsewhere (Raugei, 2011), any change in the future composition of the electric grid is expected to affect the results of the EPBT calculations for PV systems, in addition to and independently of any concurrent changes in their intrinsic energy performance. Since this issue is strictly a consequence of how EPBT is operationally defined, it also affects EROl latter is calculated according to Eqn. 4.

Finally, it is incontrovertible that the negative effects of the greenhouse gas (GHG) emissions caused by the combustion of fossil fuels in conventional thermal power plants cannot remain unaddressed much longer without taking an increasingly heavy toll on human societies in terms of external monetary and energy costs. Although hard to quantify precisely, even if it were feasible to reduce the life cycle GHG emissions of fossil fuelled electricity to a similar level as that of PV, this would result in a reduction in its $\mathrm{EROI}$, when analyzed at a suitably large scale.

The interplay of all the issues hinted at above makes the long-term prospective analysis of the EROI of PV vs. conventional energy technologies an extremely complex and inherently uncertain endeavour, which falls outside the scope of the present paper.

\section{Conclusions}

Improvements in PV technologies over the last decade have brought about notable increases in their EROI. When calculated in terms of the electricity output per unit of primary energy invested (Eqn. 2), The $\mathrm{EROI}_{\mathrm{el}}$ of $\mathrm{PV}$ ranges from 6 to 12, which 
makes it directly comparable to that of conventional thermal electricity without CCS (4 ї 24).

When instead calculated according to the often employed formula EROI $_{\mathrm{PE}-\mathrm{eq}}=$ T/EPBT (Eqn. 4), i.e. expressing the energy ǿeturnedôby PV in terms of its Đrimary Energy equivalentô the EROI of PV is up to 19 to 38, which puts it squarely in the same range of EROI as conventional fossil fuels (oil in the range of 10 to 30 ; coal in the range of 40 to 80$)$.

These new results prove that $\mathrm{PV}$ is already a viable energy option that may effectively contribute to supporting our societal metabolism, while significantly reducing the depletion of the remaining stocks of non-renewable (fossil) primary energy, and mitigating the concurrent environmental impacts in terms of global warming and polluting emissions.

However, even these remarkable results should not allow one to forget that PV, like all other renewable technologies, must still be supported by an initial investment of primary energy, which is, as of today, of fossil origin. We therefore argue that available monetary and energy resources should be funnelled in the right direction without delay, lest not enough high-EROI fossil fuels are left to support demand during times of gradual shift to renewable resources.

\section{Acknowledgements}

The authors wish to thank Dr. Robert Herendeen and the two anonymous reviewers for their insightful comments, which greatly helped in leading to this manuscript in its current form.

\section{References}

Campbell C.J., Laherrère J.H., 1998. The End of Cheap Oil. Sci. Am. 278:78-83 
Chambers R.S., Herendeen R.A., Joyce J.J., Penner P.S., 1979. Gasohol: Does it or doesn't it...produce positive net energy? Science 206:789-795.

Cleveland C., 1992. Energy quality and energy surplus in the extraction of fossil fuels in the U.S. Ecological Economics 6:139-162

Cleveland C.J., 2005. Net energy from oil and gas extraction in the United States, 1954-1997. Energy 30:769-782.

Cleveland C.J., Costanza R., Hall C.A.S., 1984. Kaufmann R. Energy and the U.S. Economy: A Biophysical Perspective. Science 225:890-897

Cleveland CJ., 1992. Energy quality and energy surplus in the extraction of fossil fuels in the U.S. Ecol. Econ. 6:139ï 62.

Denholm P., Margolis R.M., 2006. Evaluating the limits of solar photovoltaics (PV) in electric power systems utilizing energy storage and other enabling technologies. Energy Policy 35:4424-4433.

Dones R., Bauer C., Röder A., 2007. Kohle. In: Dones R. (Ed.), Sachbilanzen von Energiesystemen: Grundlagen für den ökologischen Vergleigh von Energiesystemen und den Einbezug von Energiesystemen on Ökobilanzen für die Schweiz. Ecoinvent Report No. 6-VI, Swiss Centre for Life Cycle Inventories, Dübendorf, $\mathrm{CH}$.

Ecoinvent, 2011. Ecoinvent v.2. Swiss Centre for Life Cycle Inventories. $<$ <ttp://www.ecoinvent.org>

European Photovoltaic Industry Association/GREENPEACE, 2008. Solar Generation V ï Solar electricity for over one billion people and two million jobs by 2020. The Netherlands / Belgium. <http://www.epia.org>

Fthenakis V.M., Alsema E., 2006. Photovoltaics Energy Payback Times, Greenhouse Gas Emissions and External Costs: 2004ï early 2005 Status. Prog. Photovolt. Res. Appl. 14:275ï 280 
Fthenakis V.M., Held M., Kim H.C., Raugei M., 2009. Update of Energy Payback Times and Environmental Impacts of Photovoltaics. 24 ${ }^{\text {th }}$ European Photovoltaic Solar Energy Conference and Exhibition; Hamburg, Germany.

Fthenakis V.M., Kim H.C., 2011. Photovoltaics: Life-cycle analyses. Solar Energy 85(8): 1609-1628

Fthenakis V., Frischknecht R., Raugei M., Kim H. C., Alsema E., Held M., de WildScholten M., 2011. Methodology Guidelines on Life Cycle Assessment of Photovoltaic Electricity, $2^{\text {nd }}$ edition, IEA PVPS Task 12, International Energy Agency Photovoltaic Power systems Programme

Gagnon, N., Hall C.A.S., Brinker L., 2009. A preliminary investigation of the energy return on energy invested for global oil and gas extraction. Energies 2: 490 ï 503.

Guilford M.C., Hall C.A.S., Oæonnor P., Cleveland C.J., 2011. A new long term assessment of energy return on investment (EROI) for U.S. oil and gas discovery and production. Sustainability 3(10):1866-1887

Hall C.A.S., 2008. The Energy Return of (Industrial) Solar - Passive Solar, PV, Wind and Hydro. Appendix G-2: Photovoltaics. The Oil Drum: Net Energy. <http://www.theoildrum.com/node/3910>

Hall C.A.S., Cleveland C.J., 1981. Petroleum Drilling and Production in the United States: Yield per Effort and Net Energy Analysis. Science 211:576-579

Hall C.A.S., Day J.W., 2009. Revisiting the Limits to Growth After Peak Oil. Am. Sci. $97: 230-237$

Hall C.A.S., Powers R., Schoenberg W., 2008. Peak Oil, EROI, Investments and the Economy in an Uncertain Future. In: Pimentel D., editor. Biofuels, Solar and Wind as Renewable Energy Systems: Benefits and Risks: The Netherlands: Springer Science, p. 109-132 
Heinberg R., 2009. Searching for a miracle. NNet energyò limits \& the fate of industrial society; Post Carbon Institute. <http://www.postcarbon.org/report/44377searching-for-a-miracle>

Held M., Ilg R., 2011. Update of environmental indicators and energy payback time of CdTe PV systems in Europe. Prog. Photovolt: Res. Appl. 19:614ï 626

Herendeen, R. 2004. Net energy analysis: concepts and methods. In C. J. Cleveland, ed., Encyclopedia of Energy, pp. 283-289. Elsevier

Herendeen, R. 1988. Net energy considerations, pp. 255-273. In R. West and F. Kreith, eds., Economic Analysis of Solar Thermal Energy Systems. MIT Press.

International Energy Agency. Statistics \& Balances, 2008. $<$ http://www.iea.org/stats/index.asp>

Jungbluth N., 2007. Erdöl. In: Dones R. (Ed.), Sachbilanzen von Energiesystemen: Grundlagen für den ökologischen Vergleigh von Energiesystemen und den Einbezug von Energiesystemen on Ökobilanzen für die Schweiz. Ecoinvent Report No. 6-IV, Swiss Centre for Life Cycle Inventories, Dübendorf, $\mathrm{CH}$.

Kautto N., Jaeger-Waldau A., 2009. Renewable Energy Snapshots. EC Joint Research Centre. <http://re.jrc.ec.europa.eu/refsys/pdf/RE\%20Snapshots\%202009.pdf>

King C.W., 2010. Energy intensity ratios as net energy measures of United States energy production and expenditures. Environmental Research Letters 5:044006

King C.W., Hall C.A.S., 2011. Relating financial and energy return on investment. Sustainability 3(10):1810-1832

Kubiszewski I., Cleveland C.J., 2009. Energy return on investment (EROI) for photovoltaic energy. In: Cleveland C.J. (editor). Encyclopedia of Earth. <http://www.eoearth.org/article/Energy_return_on_investment_(EROI)_for_photovolt aic_energy> 
Kubiszewski I., Cleveland C.J., Endres P.K., 2010. Meta-analysis of net energy return for wind power systems. Renewable Energy 35(1):218-225

Leach, G. 1975. Net energy-is it any use? Energy Policy 3:332-344.

Lewis N.S., 2007. Toward Cost-Effective Solar Energy Use. Science 315:798-801

Lloyd B., Forest A.S., 2010. The transition to renewables: Can PV provide an answer to the peak oil and climate change challenges? Energy Policy 38(11):73787392

Mason J., Hansen T., Fthenakis V.M., Zweibel K., 2008. Coupling PV and CAES Power Plants to Transform Intermittent PV Electricity into a Dispatchable Electricity Source. Prog. Photovolt. Res. Appl. 16:649-668

Mulder K., Hagens N.J., 2008. Energy Return on Investment: Toward a Consistent Framework. Ambio 37(2):74-79

Murphy D.J., Hall C.A.S., 2010. Year in review ï EROI or energy return on (energy) invested. Ann. N.Y. Acad. Sci. 1185:102-118

Murphy,D.J. and Hall,C.A.S., 2011. Energy return on investment, peak oil, and the end of economic growth. Ann. N.Y. Acad. Sci. 1219:52-72

NASA, 2008. Atmospheric Science Data Center. Surface meteorology and Solar Energy: Global Data Sets. <http://eosweb.larc.nasa.gov>

Nikolakakis T., Fthenakis V., 2011. The optimum mix of electricity from wind- and solar-sources in conventional power systems: Evaluating the case for New York State. Energy Policy 39:6972-6980.

Pickard W., Hansing N.J., Shen A.Q., 2009. Can large-scale advanced-adiabatic compressed air energy storage be justified economically in an age of sustainable energy? J. Ren. Sust. Energy 1:033102-1: 033102-10 
Pimm A., Garvey S., 2009. Analysis of flexible fabric structures for large-scale subsea compressed air energy storage. J. Phys.: Conf. Ser. 181:012049

Raugei M., 2011. Energy Pay-Back Time: methodological caveats and future scenarios. Prog. Photovolt: Res. Appl., in press

Raugei M., Bargigli S., Ulgiati S., 2007. Life cycle assessment and energy pay-back time of advanced photovoltaic modules: CdTe and CIS compared to poly-Si. Energy $32: 1310-1318$

Slesser M. (ed.), 1974. Energy Analysis Workshop on Methodology and Conventions, 89 p. IFIAS, Stockholm, Sweden. 